\title{
Sit4-associated protein is required for pathogenicity of Leptosphaeria maculans on Brassica napus
}

\author{
Andrew S. Urquhart and Alexander Idnurm \\ School of BioSciences, University of Melbourne, VIC, 3010, Australia
}

Correspondence: Alexander Idnurm, Room 105 BioSciences 2, School of BioSciences, University of Melbourne VIC, 3010. Phone +61 3 83442221; Fax +61 3 93475460; Email alexander.idnurm@unimelb.edu.au

\section{Acknowledgments}

We thank Angela Van de Wouw for carrying out the genetic crosses, and Barbara Howlett and Kylie Boyce for comments and suggestions on the manuscript. This research was supported by the Australian Grains Research and Development Corporation. 


\title{
Sit4-associated protein is required for pathogenicity of Leptosphaeria maculans
}

\section{on Brassica napus}

\begin{abstract}
An insertional mutant with reduced pathogenicity on Brassica napus was identified in the plant pathogenic fungus Leptosphaeria maculans. The transfer-DNA molecule from Agrobacterium tumefaciens inserted into a gene encoding a protein with similarity to SIT4-associated proteins (SAP). In contrast to Saccharomyces cerevisiae which has four members of the SAP family, there is a single copy of the gene in L. maculans. The mutant had normal spore production and spore germination, but altered hyphal branching, suggesting that nutrient signaling is impaired in the strain. This is the first time that a SAP gene has been mutated in a filamentous fungus and links the function of SAP proteins to plant pathogenesis and hyphal branching.
\end{abstract}

Keywords: canola, insertional mutagenesis, sapl, target of rapamycin 


\section{Introduction}

The Dothideomycete Leptosphaeria maculans is a major burden on the canola (Brassica napus) industry worldwide because it causes the disease "blackleg", which results in severe yield loss [10]. Antifungal targets in this species, in particular those genes that are required by the fungus during pathogenesis, are being sought by techniques that include insertional mutagenesis [28].

Despite significant effort, only nine genes required for pathogenicity on B. napus have been identified in L. maculans. These encode a predicted isocitrate lyase [14], a gene of unknown function [15], 3-ketoacylCoA thiolase [8], a plasma membrane $\mathrm{H}^{+}$-ATPase [24], a GPI-anchor biosynsthesis pathway gene [25], UDPglucose-4-epimerase [26], a gene affecting cell wall integrity [35], a homolog of the SNF1 protein kinase [9] and the StuA transcription factor [31]. The majority of these genes have been identified using insertional mutagenesis. The slow rate of gene discovery using insertional mutagenesis in part relates to the fact that the inserted DNA often occurs between rather than within genes and multiple insertions may occur simultaneously $[3,5,15]$. This complicates the analysis of resulting pathogenicity mutants. For example, a reduction in pathogenicity may result from misregulation of gene expression, as in the case of 3-ketoacyl-CoA thiolase [8]. Furthermore, another problem encountered when using an insertional mutagenesis approach is that the loss of pathogenicity may not be due to the disrupted gene itself but due to background mutations at other positions in the genome. Blaise et al. found that only $50 \%$ of mutants had loss of pathogenicity phenotypes segregating with the T-DNA insert [3]. Another consideration is that a second gene may be disrupted elsewhere in the genome by a second T-DNA insertion. Analysis of gene function using targeted gene disruption is equally problematic, with targeting being at rates lower than $0.25 \%$ of transformants [16]. However, as more pathogenicity genes are discovered, the types of processes involved in the pathogenicity of L. maculans will become clearer, potentially leading to new strategies to control blackleg disease.

In many plant pathogenic fungi, genes involved in signalling in response to the external environment are of key importance to pathogenesis. An example of a well studied family of such genes is the mitogen activated protein kinases. Mutants in these genes have reduced pathogenicity in a number of species including Bipolaris sorokiniana [20] and Magnaporthe oryzae [37].

Another type of signalling kinase, sucrose non-fermenting protein kinase 1 (SNF1), has been identified as being required for virulence in L. maculans [9]. Feng et al. found that in L. maculans SNF1 expression was induced by the non-preferred carbon souce pectin, which agrees with the function of the Saccharomyces cerevisiae homolog that is to derepress genes that are repressed in the presence of the preferred carbon source 
glucose $[6,9]$. This finding indicates that signalling in response to environmental stimuli, in particular nutrient availability, might be important to the ability of L. maculans to cause disease.

In this paper we describe an insertional mutant in a Sit4-associated protein homolog (SAP) that shows markedly reduced pathogenicity. SAPs are part of the Target of Rapamycin (TOR) signalling pathway and associate with the protein kinase, Sit4.

\section{Materials and methods}

\section{Leptosphaeria maculans isolates and culture conditions}

The L. maculans isolate D5 (M1; IBCN18) was used for insertional mutagenesis and isolate D9 (05MGPS049) was used for mating experiments. L. maculans was subcultured on V8 agar plates [10\% V8 juice (Campbell's), $2 \%$ agar, $\mathrm{pH} 6]$ at $22^{\circ} \mathrm{C}$ with a $12 \mathrm{~h}$ night/day cycle. Hyphal and colony morphology was observed on both $\mathrm{V} 8$ agar and on water agar. Asexual pycnidiospores from sporulating cultures of L. maculans were harvested by scraping the surface of V8 agar plates with sterile water, and subsequently filtered through Miracloth (Millipore). Mycelial cultures for DNA extraction were set up in liquid V8 juice medium and incubated for one week at room temperature.

\section{Agrobacterium-mediated transformation of L. maculans}

A plasmid containing a hygromycin resistance gene was transformed into Agrobacterium tumefaciens strain EHA105 by electroporation. This plasmid, pLAU12, is modified from pPZPHygHindX [8] for the overexpression of genes in L. maculans (manuscript in preparation). These additional sequences do not modify the T-DNA transfer capabilities or selection system. A. tumefaciens-mediated transformation of L. maculans was carried out and transformant were selected using an agar overlay method described previously [11]. Antibiotics in the overlay were cefotaxime $(200 \mu \mathrm{g} / \mathrm{ml})$ and hygromycin $(100 \mu \mathrm{g} / \mathrm{ml})$.

\section{Pathogenicity tests on Brassica napus cotyledons}

Cotyledons of $B$. napus cultivar Westar were inoculated 10 days after seed germination by first wounding the leaves with modified tweezers (four inoculations per plant) then applying $10 \mu \mathrm{l}$ of pycnidiospores $\left(\sim 5 \times 10^{6}\right.$ spores/ml); 150 transformants were screened. After 14 days cotyledons were photographed and disease was assessed by measuring the area of necrosis. Image $\mathbf{J}$ software [30] was used to assess disease for 70, 76, 85 and 80 inoculation points for the wild type D5 isolate, the T-DNA insertional mutant, and complementation strains 
SAPC1_1 and SAPC9_1, respectively. Student's $t$-tests were used to determine statistical significance for $P<$ 0.05 .

\section{Trypan blue staining of infected cotyledons}

Hyphae in infected cotyledons (14 days post inoculation) were stained with trypan blue [18]. Cotyledons were immersed in staining solution (10 ml lactic acid, $10 \mathrm{~g}$ phenol, $10 \mathrm{ml}$ glycerol, $10 \mathrm{mg}$ trypan blue (Sigma-Aldrich T0776), $10 \mathrm{ml} \mathrm{H}_{2} \mathrm{O}$ mixed 1:1 with ethanol immediately prior to use) and boiled for several minutes. Cotyledons were destained in chloral hydrate $\left(70 \% \mathrm{w} / \mathrm{w}\right.$ in $\left.\mathrm{H}_{2} \mathrm{O}\right)$ for one week then observed under a compound microscope.

\section{Genomic DNA extractions from $L$. maculans mycelia}

Mycelia ( 100 mg) were freeze-dried then ground on a MM 300 mixer mill (Retsch Instruments) using tungsten carbide beads at $30 \mathrm{~Hz}$ for $30 \mathrm{~s}$. Homogenized tissue was mixed with DNA isolation buffer $(0.5 \mathrm{M} \mathrm{NaCl}, 10$ mM EDTA, 1\% SDS, $10 \mathrm{mM}$ Tris-HCl) in a phase lock-tube. Phenol:chloroform (1:1) was added and the samples were centrifuged for $15 \mathrm{~min}$ at $13000 \mathrm{rpm}$. Chloroform was added to the supernatant and the samples were centrifuged for $10 \mathrm{~min}$ at $13000 \mathrm{rpm}$. DNA in the supernatant was precipitated by adding 0.6 volume of isopropanol and pelleting by centrifugation at $13000 \mathrm{rpm}$ for $5 \mathrm{~min}$.

\section{Inverse PCR}

Inverse PCR [23] was used to identify the site of T-DNA insertions in the genome of the T-DNA insertional mutant. Genomic DNA was digested with PstI restriction enzyme (Promega) at $37^{\circ} \mathrm{C}$ for $3 \mathrm{~h}$ and the digested fragments circularised using T4 DNA ligase (Promega). PCR reactions were set up off the circularised template using ExTaq polymerase (Takara) and the primer pairs M13F (5' GTAAAACGACGGCCAG 3’) / ai76 (5' AACAGTTGCGCAGCCTGAATG 3') and M13R (5’ AACAGCTATGACCATG 3’) / ai077 (5' AGAGGCGGTTTGCGTATTGG 3'). The location of the insert was confirmed by a second PCR using primers AU130 (5’ ACAACAGGCCAGGGACTGG 3') and ai077. Amplicons were sequenced and the sequences were matched to the L. maculans genome ([29]; available through http://genome.jgi.doe.gov) using BLAST [1].

\section{cDNA cloning and sequencing}

Mycelium of isolate D5 was cultured in a defined minimal medium [34] with 2\% glucose as the carbon source. RNA was isolated using Trizol reagent following the manufacturer's guidelines (Invitrogen). cDNA 
was synthesized using SuperScript IV (Invitrogen). The full length open reading frame was amplified with primers MAI0152 (5’ GGATCCATGTTTTGGCGCTTCGGC 3') and MAI0153 (5' GGATCCTTATCGATAGTCCATGTCAGC 3') and amplicons were cloned into the pCR ${ }^{\mathrm{TM}}$ 2.1-TOPO ${ }^{\circledR}$ TA vector (Invitrogen). The cloned fragments were sequenced.

\section{Crosses and genetic segregation analysis}

The Leptosphaeria T-DNA insertional mutant was crossed to isolate D9. Plugs cut from the two isolates were placed on V8 agar mating medium $\left[20 \% \mathrm{~V} 8, \mathrm{CaCO}_{3}(0.2 \%)\right.$, agar $\left.(2 \%)\right]$. Strains were grown for one week at $22^{\circ} \mathrm{C}$ with a $12 \mathrm{~h}$ photoperiod then overlaid with water agar $\left(1 \%\right.$ agar). After 4-6 weeks incubation at $14^{\circ} \mathrm{C}$ with a $12 \mathrm{~h}$ black-light photoperiod, pseudothecia were produced and individual ascospores were isolated. Progeny were screened for resistance to hygromycin, colony morphology and pathogenicity on B. napus. In addition, the mating type of each of the progeny was determined by PCR as described previously [7].

\section{Complementation of the Leptosphaeria mutant strain}

The T-DNA insertion in the Leptosphaeria pathogenicity mutant was located in the homolog of a gene encoding a Sit4-associated protein homolog. The mutant was complemented with the wild type allele. The genomic sequence of the L. maculans sapl gene (Lema_T071490) from isolate v23.1.3 was obtained from the Joint Genome Institute database. The predicted intron-exon sequence was corrected by mapping RNA-seq reads [21] onto the gene using Integrative Genomics Viewer [33] and from sequencing cDNA clones. The gene information available on the JGI database contained $150 \mathrm{bp}$ of unknown sequence. Covering this region using a combination of Sanger sequencing and next generation sequencing reads revealed that this $150 \mathrm{bp}$, in addition to 21 bp and 268 bp upstream and downstream, respectively, is not present in isolate D5 (Fig S1). Seven hundred and forty-one bp of sequence upstream of the start codon was taken as the promoter and $819 \mathrm{bp}$ of sequence downstream of the stop codon as the terminator. Three PCR fragments covering the gene were obtained from isolate D5: one corresponding to the promoter of the gene (AU172 5'

GCCTCACCGCGGCCCATGGTCATGCCCACCCACTTTTGC 3’’ and AU138 5’

GCCGAAGCGCCAAAACATGG 3'), one corresponding to the coding region of the gene (AU131 5'

ATGTTTTGGCGCTTCGGCGG $3^{\prime}$ and AU141 5’ TTATCGATAGTCCATGTCAGC $3^{\prime}$ ) and a third to the terminator (AU173 5’ GCTGACATGGACTATCGATAATCC 3’ and AU174 5'

GTCATCTTCTGTCGAATCGGTACCCAGCTATCCCGATCCCTTGCCG 3'). The three fragments of the 
gene were then cloned using Gibson assembly (New England Biolabs) into plasmid pPZPNat1, which includes the gene for nourseothricin acetyltransferase for selection [12], linearized with XbaI and XhoI. Agrobacteriummediated transformation was used to transform this complementation construct into the Leptosphaeria SAP mutant strain with selection on medium containing nourseothricin $(200 \mu \mathrm{g} / \mathrm{ml}$ in the overlay). Two independent transformants, named SAPC1_1 and SAPC9_1, were characterized.

\section{Radial growth and pycnidiospore germination assays}

The in vitro growth rates of strains were determined by placing $2 \mu \mathrm{l}$ of pycnidiospores $\left(10^{7}\right.$ spores $\left./ \mathrm{ml}^{\text {in }} \mathrm{H}_{2} \mathrm{O}\right)$ onto the center of agar plates. A cross was drawn on the bottom of the plate and growth (at $22^{\circ} \mathrm{C}$ with a 12 hour photoperiod) along each of the four lines was measured at regular intervals from day 4 to day 16 . Two different agar media were used: water agar $\left(1 \%\right.$ agar in $\left.\mathrm{H}_{2} \mathrm{O}\right)$ and clarified V8 juice medium. The colonies grown on water agar did not show sufficient contrast to the media to be photographed, so the hyphae were stained using lactophenol cotton blue (0.05 g cotton blue, $20 \mathrm{~g}$ phenol, $20 \mathrm{ml}$ lactic acid, $40 \mathrm{ml}$ glycerol and $20 \mathrm{ml}$ of distilled $\mathrm{H}_{2} \mathrm{O}$ ) by flooding the stain over the surface of the media and removing excess stain after several minutes.

Spore germination was assessed in vitro with a method adapted from that used by [9]. Spores (200 $\mu 1$ of $1 \times 10^{7}$ spores $/ \mathrm{ml}$ in distilled $\mathrm{H}_{2} \mathrm{O}$ ) were mixed with $10 \mathrm{ml}$ of molten $0.8 \% \mathrm{~V} 8$ agar. The mixture was poured into a petri dish and kept at $22^{\circ} \mathrm{C}$ in a dark incubator. After $48 \mathrm{~h}$, a portion of agar was cut from the center of the plate, stained with lactophenol cotton blue, placed on a microscope slide and then pressed under a coverslip. Approximately 100 spores were counted under a compound light microscope and the proportion of spores that had germinated was recorded. Bright field images of hyphae in vitro and in planta were taken using a Leica DM2500 compound microscope with a Leica DC 300F digital camera.

\section{Results}

\section{Isolation of a mutant of $L$. maculans with reduced pathogenicity on canola}

One strain with reduced pathogenicity was identified after screening 150 strains derived from A. tumefaciens transformation. The mutant caused markedly reduced disease on cv. Westar, with an average lesion area of 2.1 $\mathrm{mm}^{2}$ compared to $19.7 \mathrm{~mm}^{2}$ for the wild type (Figs $1 \mathrm{~A}$ and 2). This difference was statistically significant as determined by a Student's $t$-test. In cotyledons infected with the wild type L. maculans isolate, long hyphae 
penetrated far into the leaf, whereas in the mutant such hyphae were rarely seen. In cases where a small lesion had formed, the hyphae never extended far from the initial inoculation point and were highly branched (Fig 1B).

\section{Identification of the T-DNA insertion site within a gene (sap1) encoding a Sit4-associated protein homolog} One flank of the T-DNA insertion was obtained by inverse PCR. Sequencing and subsequent BLAST of the inverse PCR product indicated that the insert was located on SuperContig 7 of the L. maculans genome, into the first exon 307 bp downstream of the start codon of the gene Lema_T071490.1, which is annotated as "similar to Sit4-associated protein

(SAP185)". A second PCR was used to define the other side of the insertion and revealed a deletion of 22 nucleotides from the genomic DNA of L. maculans (Fig 3). Due to ambiguities in the annotation of the gene from the genome sequence project, the coding regions of the sapl gene were confirmed by isolating and sequencing cDNA molecules. An annotated version of the DNA sequence and the coding region for the sapl gene is presented in Fig S1. As a consequence of the T-DNA insertion, the predicted protein is truncated to just 119 amino acids, of which 102 match to the start of the wild type SAP1 sequence of 964 amino acids.

\section{The growth rate of the SAP mutant is altered}

The growth rate of the Leptosphaeria SAP mutant strain, as measured by colony diameter, was reduced on both water agar and V8 agar. On water agar the growth rate of the wild type was $2.1 \mathrm{~mm} /$ day while the SAP mutant grew at $1.0 \mathrm{~mm} /$ day (Fig 4A). On V8 agar the wild type grew at $1.6 \mathrm{~mm} /$ day compared to $0.78 \mathrm{~mm} /$ day in the SAP mutant (Fig 4B). This difference is attributed to hyphal growth rather than a germination defect, because the spores of the wild type and the Leptosphaeria SAP mutant had a similar germination frequency after $48 \mathrm{~h}$ in two independent experiments (93\% and 74\% for wild type spores and $94 \%$ and $82 \%$ for the SAP mutant spores).

\section{Hyphal and colony morphology are impaired in the SAP mutant}

The morphology of the Leptosphaeria SAP mutant colonies grown on V8 agar differed from the wild type due to the presence of short hyphal branches, giving the mycelium a slightly 'fluffy' appearance (Fig 5). There was considerable difference between the Leptosphaeria SAP mutant and the wild type on water agar because the 
mutant did not show the reduction in branching displayed by the wild type (Fig 5). The wild type colony was sparse, consisting of long trailing hyphae extending into the medium, whereas the Leptosphaeria SAP mutant formed a smaller, denser colony of highly branched hyphae.

\section{Genetic segregation and complementation experiments confirm that mutation of the sap1 gene is responsible for the mutant phenotypes}

Twenty-four progeny were obtained from a cross between the Leptosphaeria SAP mutant and isolate D9: 14 were hygromycin-sensitive and 10 were hygromycin-resistant. This ratio is consistent with a single T-DNA insertion event into the genome. Thirteen out of the 14 hygromycin sensitive progeny were able to cause disease to a similar extent to that of a wild type isolate and all ten of the hygromycin-resistant progeny showed reduced pathogenicity. Of the hygromycin-sensitive progeny, 10 showed a wild type phenotype in vitro (fast growth with a smooth colony edge), three showed a reduced growth rate but normal hyphal morphology, and one showed an unusual hyphal morphology somewhat similar to the phenotype of the Leptosphaeria SAP mutant. Of the hygromycin-resistant progeny, seven showed a branching phenotype similar to the Leptosphaeria SAP mutant, two showed an intermediate phenotype in which the hyphae appeared only slightly more branched and one isolate showed little growth. The mating types of the progeny were assessed by PCR, indicating that the progeny set includes recombinant classes. Of the hygromycin sensitive isolates six were MAT1-2 and eight were MAT1-1. Of the resistant progeny six were MAT1-1 and four were MAT1-2.

A wild type copy of the sapl gene was transformed into the Leptosphaeria SAP mutant. Complementation with the wild type copy of the gene restored the pathogenicity of the mutant back to the wild type level in two independently complemented strains (average lesion areas of $18.2 \mathrm{~mm}^{2}$ in strain SAPC9_1 and $21.7 \mathrm{~mm}^{2}$ in strain SAPC1_1, Figs 1A and 2). These values were not statistically significantly different from the wild type as determined by a Student's $t$-test. Additionally the complemented isolates had the equivalent growth rates as wild type (Fig 4), and they had a smooth colony edge and lacked the branching hyphal protrusions present in the mutant (Fig 5).

\section{Discussion}

Of 150 insertional mutants of L. maculans screened on B. napus cotyledons, one transformant was identified as having reduced pathogenicity. In a cross with this transformant, the T-DNA segregated with the reduction of pathogenicity. The mutant phenotype was rescued by complementation with a wild-type copy of 
the SAP gene. Together, these data indicate that the T-DNA insertion is responsible for the reduction of pathogenicity. Bourras et al. showed that T-DNA insertion is biased towards regulatory regions of genes, including promoters, and that this T-DNA integration pattern can be explained by the existence of microhomologies between promoter sequences and the T-DNA left border flanking sequence [5]. Interestingly, microhomologies to the T-DNA left and right borders were also detected at the T-DNA insertion site of our transformant which might explain why the T-DNA has inserted into the coding region of the sapl gene.

Although the Leptosphaeria SAP mutant grew more slowly than the wild type isolate, this does not solely account for the reduction of pathogenicity phenotype because wild type L. maculans isolates show a wide range of growth rates. A more likely contributing factor to the reduction in pathogenicity is the increased branching phenotype seen in the hyphae of the Leptosphaeria SAP mutant. This phenotype was most obvious on the low nutrient water agar where hyphae of the wild type and complemented strains were markedly less branched than that of the mutant. This in vitro phenotype is reflected in vivo during infection. When inoculated onto plants the wild type produces long penetrating hyphae that extend into the leaf, while the Leptosphaeria SAP mutant was impaired in this process..

The disrupted gene in the Leptosphaeria SAP mutant is a homolog of a component in the target of rapamycin (TOR) signaling pathway. TOR signaling plays an important regulatory role in eukaryotic cells. In the model fungus $S$. cerevisiae TOR signaling couples cellular metabolism to nutrient availability [27]. TOR promotes Tap42 to form complexes with type 2A and type 2A-like phosphatases [36]. One such type 2A-like phosphatase is Sit4. TOR is active when nutrients are available, which results in the association of Sit4 and Tap42 to form an inactive complex. On the other hand, when nutrients are limited, TOR is inactive and the TAP42-Sit4 complex dissociates leaving the Sit4 phosphatase active [2]. One of the roles of the active Sit4 protein in S. cerevisiae is to dephosphorylate the transcription factor Gln3, which results in untethering from the cytoplasmic protein Ure2 and subsequent localization into the nucleus leading to transcription of genes needed for adaptation to nutrient stress [2]. In addition to Tap42, in both S. cerevisiae and F. graminearum Sit4 also interacts with a number of other proteins including Sit4-associated proteins (SAPs) $[22,36]$. S. cerevisiae contains four SAP homologs - SAP185, SAP190, SAP155 and SAP4. This contrasts to L. maculans in which there is only a single SAP homolog in the genome, as assessed by BLAST.

Deletion of Sit4 results in serious growth defects or loss of pathogenicity in a number of fungi including S. cerevisiae [22], the human pathogens Aspergillus fumigatus [4] and Candida albicans [19] and the filamentous plant pathogen Fusarium graminearum [36]. SAP loss-of-function mutants have only been reported 
for $S$. cerevisiae $[17,22,27]$. Deletion of either SAP185 or SAP190 alone did not cause a significant decrease in growth rate. However, in the sap185 sap190 double mutant, growth rate was significantly reduced. A quadruple mutant of all four SAP genes had a severe decrease in growth rate of an equivalent magnitude to a sit4 knockout. The fact that the quadruple SAP knockout in S. cerevisiae shows the same phenotype as a sit4 knockout indicates that the SAP genes function in the same pathway as Sit4.

In wild type L. maculans the degree of hyphal branching is influenced by nutrient availability in that growth when nutrients are limiting leads to reduced branching, as seen by the pattern on the low nutrient water agar. The Leptosphaeria SAP mutant showed a higher degree of branching on water agar than the wild type or complemented strains, indicating that SAP plays a role in regulating branching in filamentous fungi. As a hemibiotrophic pathogen, this fungus initially grows in the apoplast of the plant, which is not a nutrient-rich environment. This may explain the unusual branching phenotype observed during cotyledon infection.

TOR type 2A phosphatases have not previously been implicated in hyphal branching. However, another TOR target, the kinase FgSch9, regulates hyphal branching in F. graminearum [13]. Interestingly, the way in which Sch9 regulates branching differs between species: in F. graminearum the sch9 knockout has reduced branching, whereas in Candida albicans a sch 9 knockout shows an increase in branching [32].

In conclusion, in this study we have identified a new pathogenicity factor in L. maculans. Future research should explore the signaling system through which this homolog of a Sit4-associated protein integrates environmental nutrient levels to impact the ability of this fungus to cause disease on canola.

\section{References}

1. Altschul SF, Gish W, Miller W, Myers EW, Lipman DJ (1990) Basic local alignment search tool. J Mol Biol 215:403-410.

2. Beck T, Hall MN (1999) The TOR signaling pathway controls nuclear localization of nutrient-regulated transcription factors. Nature 402:689-692.

3. Blaise F, Rémy E, Meyer M, Zhou L, Narcy J-P, Roux J, Balesdent M-H, Rouxel T. (2007). A critical assessment of Agrobacterium tumefaciens-mediated transformation as a tool for pathogenicity gene discovery in the phytopathogenic fungus Leptosphaeria maculans. Fungal Genet Biol 44:123-138.

4. Bom VLP, de Castro PA, Winkelströter LK, Marine M, Hori JI, Ramalho LNZ, dos Reis TF, Goldman MHS, Brown NA, Rajendran R, Ramage G, Walker LA, Munro CA, Rocha MC, Malavazi I, Hagiwara D, Goldman GH. (2015) The Aspergillus fumigatus sitA phosphatase homologue is important for adhesion, 
cell wall integrity, biofilm formation, and virulence. Eukaryot Cell 14:728-744.

5. Bourras S, Meyer M, Grandaubert J, Lapalu N, Fudal I, Linglin J, Ollivier B, Blaise F, Balesdent M-H, Rouxel T. (2012) Incidence of genome structure, DNA asymmetry, and cell physiology on T-DNA integration in chromosomes of the phytopathogenic fungus Leptosphaeria maculans. G3 2:891-904.

6. Celenza JL, Carlson M (1984) Structure and expression of the SNF1 gene of Saccharomyces cerevisiae. Mol Cell Biol 4:54-60

7. Cozijnsen AJ, Howlett BJ (2003) Characterisation of the mating-type locus of the plant pathogenic ascomycete Leptosphaeria maculans. Curr Genet 43:351-357.

8. Elliott CE, Howlett BJ (2006) Overexpression of a 3-ketoacyl-CoA thiolase in Leptosphaeria maculans causes reduced pathogenicity on Brassica napus. Mol Plant-Microbe Interact 19:588-596.

9. Feng J, Zhang H, Strelkov SE, Hwang S-F (2014) The LmSNF1 gene is required for pathogenicity in the canola blackleg pathogen Leptosphaeria maculans. PLoS One 9:e92503.

10. Fitt BDL, Brun H, Barbetti MJ, Rimmer SR (2006) World-wide importance of Phoma stem canker (Leptosphaeria maculans and L. biglobosa) on oilseed rape (Brassica napus). Eur J Plant Pathol 114:3-15.

11. Gardiner DM, Howlett BJ (2004) Negative selection using thymidine kinase increases the efficiency of recovery of transformants with targeted genes in the filamentous fungus Leptosphaeria maculans. Curr Genet 45:249-255.

12. Gardiner DM, Jarvis RS, Howlett BJ (2005) The ABC transporter gene in the sirodesmin biosynthetic gene cluster of Leptosphaeria maculans is not essential for sirodesmin production but facilitates selfprotection. Fungal Genet Biol 42:257-263.

13. Gu Q, Zhang C, Yu F, Yin Y, Shim W-B, Ma Z (2015) Protein kinase FgSch9 serves as a mediator of the target of rapamycin and high osmolarity glycerol pathways and regulates multiple stress responses and secondary metabolism in Fusarium graminearum. Environ Microbiol 17:2661-2676.

14. Idnurm A, Howlett BJ (2002) Isocitrate lyase is essential for pathogenicity of the fungus Leptosphaeria maculans to canola (Brassica napus). Eukaryot Cell 1:719-724.

15. Idnurm A, Howlett BJ (2003) Analysis of loss of pathogenicity mutants reveals that repeat-induced point mutations can occur in the Dothideomycete Leptosphaeria maculans. Fungal Genet Biol 39:31-37.

16. Idnurm A, Taylor JL, Pedras MSC, Howlett, BJ (2003) Small scale functional genomics of the blackleg fungus, Leptosphaeria maculans: analysis of a 38 kb region. Australas Plant Pathol 32:511-519.

17. Jablonowski D, Täubert J-E, Bär C, Stark MJR, Schaffrath R (2009). Distinct subsets of Sit4 
holophosphatases are required for inhibition of Saccharomyces cerevisiae growth by rapamycin and zymocin. Eukaryot Cell 8:1637-1647.

18. Keogh RC, Deverall BJ, McLeod S (1980) Comparison of histological and physiological-responses to Phakopsora pachyrhizi in resistant and susceptible soybean. T Brit Mycol Soc 74:329-333.

19. Lee C-M, Nantel A, Jiang LH, Whiteway M, Shen S-H (2004) The serine/threonine protein phosphatase SIT4 modulates yeast-to-hypha morphogenesis and virulence in Candida albicans. Mol Microbiol 51:691709.

20. Leng Y, Zhong S (2015) The role of mitogen-activated protein (MAP) kinase signaling components in the fungal development, stress response and virulence of the fungal cereal pathogen Bipolaris sorokiniana. PLoS One 10:e0128291.

21. Lowe RGT, Cassin A, Grandaubert J, Clark BL, Van de Wouw AP, Rouxel T, Howlett BJ (2014) Genomes and transcriptomes of partners in plant-fungal-interactions between canola (Brassica napus) and two Leptosphaeria species. PLoS One 9:e103098.

22. Luke MM, Della Seta F, Di Como CJ, Sugimoto H, Kobayashi R, Arndt KT (1996) The SAPs, a new family of proteins, associate and function positively with the SIT4 phosphatase. Mol Cell Biol 16:27442755.

23. Ochman H, Gerber AS, Hartl DL (1988) Genetic applications of an inverse polymerase chain-reaction. Genetics 120:621-623.

24. Remy E, Meyer M, Blaise F, Chabirand M, Wolff N, Balesdent M-H, Rouxel T (2008a) The Lmpmal gene of Leptosphaeria maculans encodes a plasma membrane $\mathrm{H}^{+}$-ATPase isoform essential for pathogenicity towards oilseed rape. Fungal Genet Biol 45:1122-1134.

25. Remy E, Meyer M, Blaise F, Simon UK, Kuhn D, Chabirand M, Riquelme M, Balesdent M-H, Rouxel T (2008b) The Lmgpi15 gene, encoding a component of the glycosylphosphatidylinositol anchor biosynthesis pathway, is required for morphogenesis and pathogenicity in Leptosphaeria maculans. New Phytol 179:1105-1120.

26. Remy E, Meyer M, Blaise F, Simon UK, Kuhn D, Balesdent MH, Rouxel T (2009) A key enzyme of the Leloir pathway is involved in pathogenicity of Leptosphaeria maculans toward oilseed rape. Mol PlantMicrobe Interact 22:725-736.

27. Rohde JR, Campbell S, Zurita-Martinez SA, Cutler NS, Ashe M, Cardenas ME (2004) TOR controls transcriptional and translational programs via Sap-Sit4 protein phosphatase signaling effectors. Mol Cell 
Biol 24(19):8332-8341.

28. Rouxel T, Balesdent MH (2005) The stem canker (blackleg) fungus, Leptosphaeria maculans, enters the genomic era. Mol Plant Pathol 6:225-241.

29. Rouxel T et al. (2011) Effector diversification within compartments of the Leptosphaeria maculans genome affected by repeat-induced point mutations. Nat Commun 2:202.

30. Schneider CA, Rasband WS, Eliceiri, KW (2012) NIH Image to ImageJ: 25 years of image analysis. Nat Methods 9:671-675.

31. Soyer JL, Hamiot A, Ollivier B, Balesdent M-H, Rouxel T, Fudal I (2015) The APSES transcription factor $\mathrm{LmStuA}$ is required for sporulation, pathogenic development and effector gene expression in Leptosphaeria maculans. Mol Plant Pathol 16:1000-1005.

32. Stichternoth C, Fraund A, Setiadi E, Giasson L, Vecchiarelli A, Ernst JF (2011) Sch9 kinase integrates hypoxia and $\mathrm{CO}_{2}$ sensing to suppress hyphal morphogenesis in Candida albicans. Eukaryot Cell 10:502511.

33. Thorvaldsdóttir H, Robinson JT, Mesirov JP (2013) Integrative Genomics Viewer (IGV): highperformance genomics data visualization and exploration. Brief Bioinform 14:178-192.

34. Tinline, RD, Strauffer JF and Dickson JG (1960) Cochliobolus sativus III. Effects of ultraviolet radiation. Can J Bot 38:275-282.

35. Van de Wouw AP, Pettolino FA, Howlett BJ, Elliott CE (2009) Mutations to LmIFRD affect cell wall integrity, development and pathogenicity of the ascomycete Leptosphaeria maculans. Fungal Genet Biol 46:695-706.

36. Yu F, Gu Q, Yun Y, Yin Y, Xu J-R, Shim W-B, Ma Z (2014) The TOR signaling pathway regulates vegetative development and virulence in Fusarium graminearum. New Phytol 203:219-32.

37. Zhao X, Kim Y, Park G, Xu J-R (2005) A mitogen-activated protein kinase cascade regulating infectionrelated morphogenesis in Magnaporthe grisea. Plant Cell 17:1317-1329.

\section{Figure legends}

Fig. 1 Isolation of a T-DNA insertional mutant with reduced pathogenicity. (A) Representative lesions 14 days post inoculation on B. napus cv. Westar cotyledons of the wild type isolate, the Leptosphaeria SAP T-DNA 
insertional mutant, and two complemented strains (SAPC1_1 and SAPC9_1). (B) Infected cotyledon tissue stained with trypan blue. The hyphae of the wild-type infection appeared less branched and penetrated further into the cotyledon tissue. Scale bar $=0.1 \mathrm{~mm}$.

Fig. 2 Distributions of lesion sizes of four L. maculans strains 14 days post inoculation on B. napus cv. Westar. The lesions generated by the Leptosphaeria SAP mutants were in all cases only very small or not visible. A reversal back to the wild-type phenotype occurred in the two complemented strains (SAPC1_1 and SAPC9_1).

Fig. 3 Location of the T-DNA insertion within the first exon of Lema_T071490.1, 307 bp downstream of the start codon in the Leptosphaeria SAP mutant. (A) The genomic sequence at the insertion site is shown for the wild type and SAP mutant. The T-DNA replaces between 22-27 nt, with this ambiguity being due to the regions of microhomology (underlined) between the L. maculans genomic DNA and the T-DNA sequence. (B) Diagram of the position of the T-DNA insertion (bar) into the sapl gene. Black boxes represent exons and white boxes represent introns. The positions and orientation of the primers used to amplify fragments to make the complementation construct are presented as arrows.

Fig. 4 The in vitro growth rate of the Leptosphaeria SAP mutant compared to the wild type and two complemented strains (SAPC1_1 and SAPC9_1) on (A) water agar and (B) V8 juice agar media. Growth assays are from seven replicates on V8 media and three replicates on water agar. Error bars represent \pm 2 times the standard deviation.

Fig. 5 In vitro growth of L. maculans strains after 10 days. The top panel of four images are colony morphologies on clarified V8 juice agar. The middle and bottom panels are the colony edge morphologies of strains growing on clarified V8 juice or water agar. The hyphae growing on water agar were stained using lactophenol cotton blue to increase contrast. Scale bars represent $1 \mathrm{~cm}$ for the whole colonies and $750 \mu \mathrm{m}$ for colony edges. 


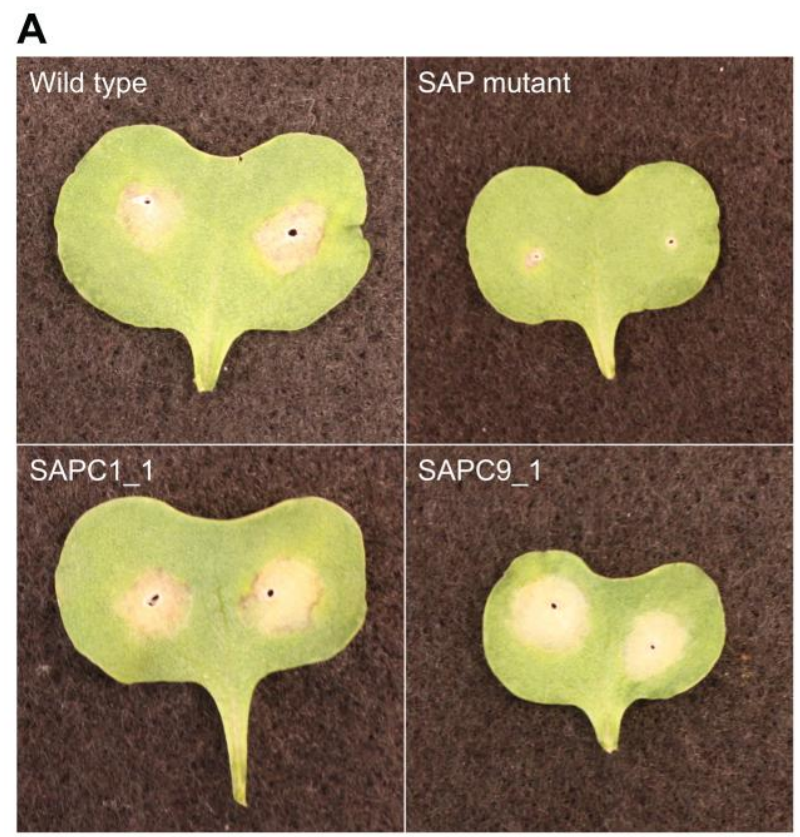

B

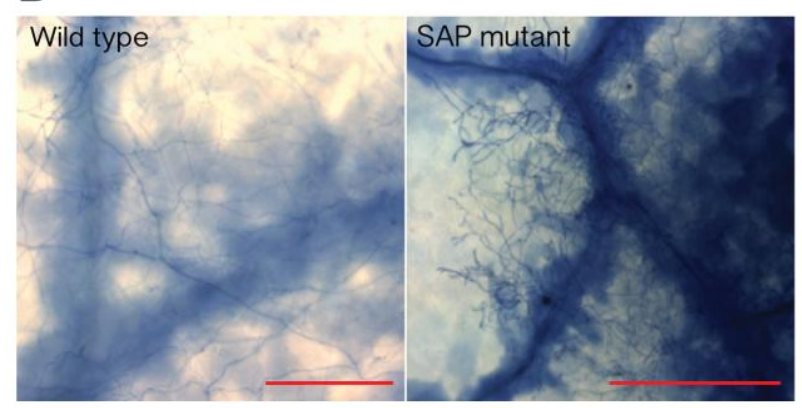

Wild type
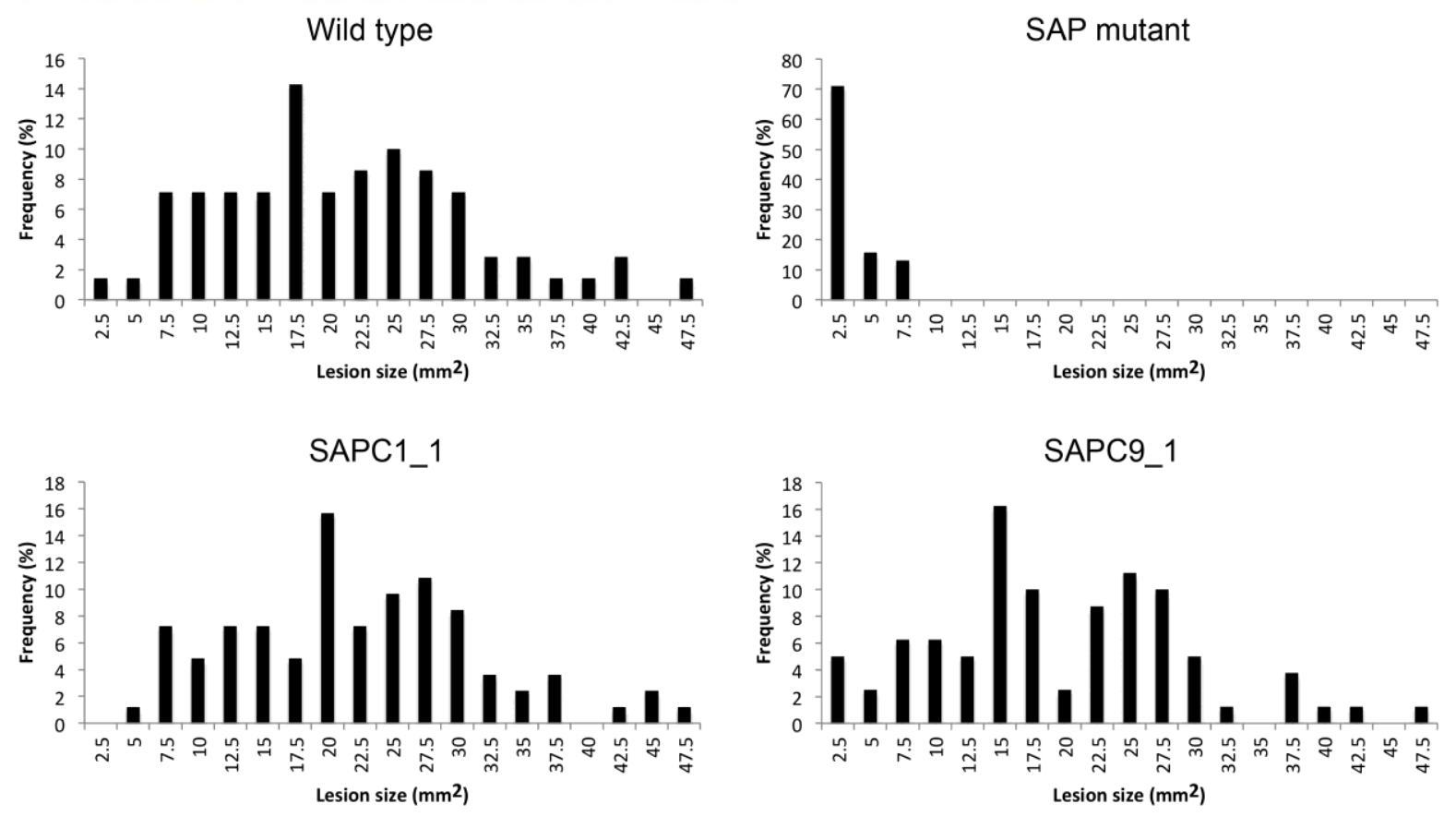


\section{A}

Wild type GGCCCGCTCCCTGTCCACCAGCAAGTCCGATGCGGGCGACAATGAGGAGAACAAGGAGGAGC Mutant GGCCCGCTCCCTGTCCACCA--------T-DNA-------TGAGGAGAACAAGGAGGAGC

B

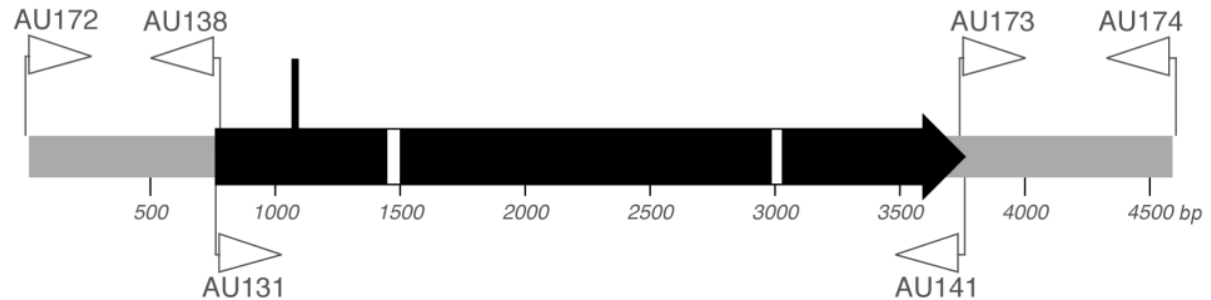

A 40

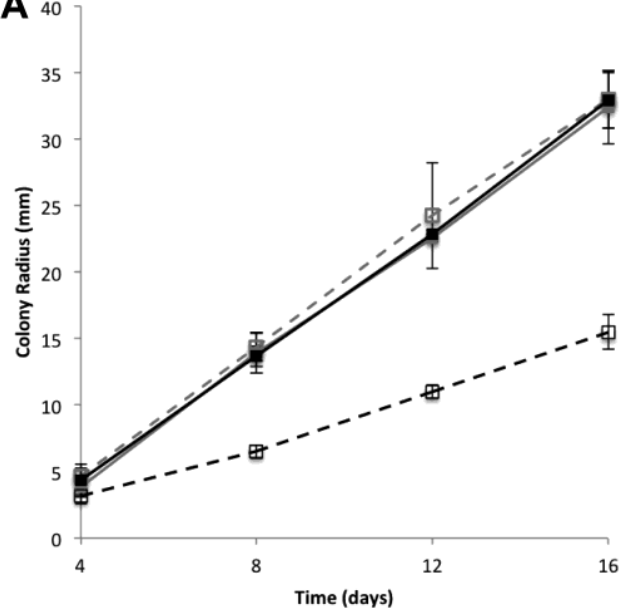

B

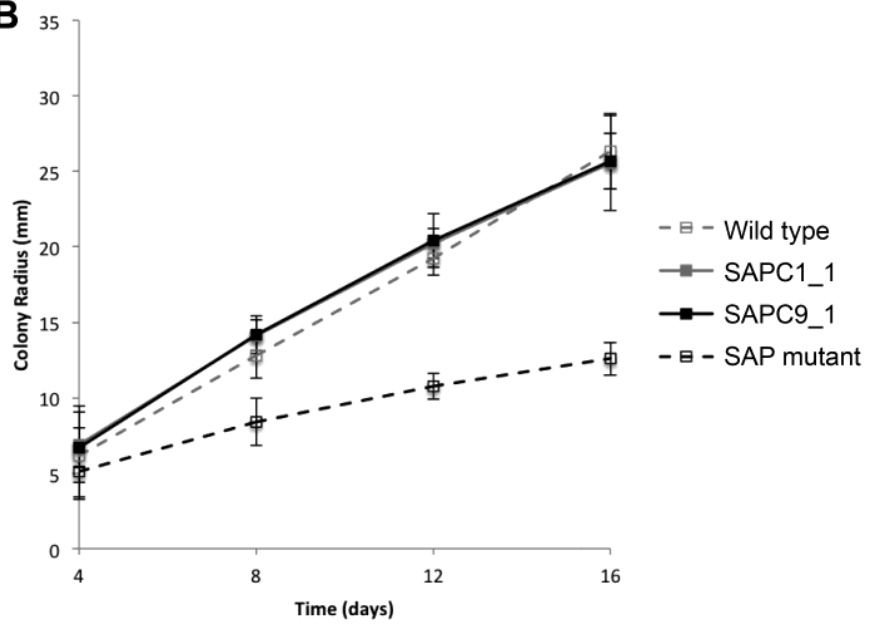

SAPC9 1

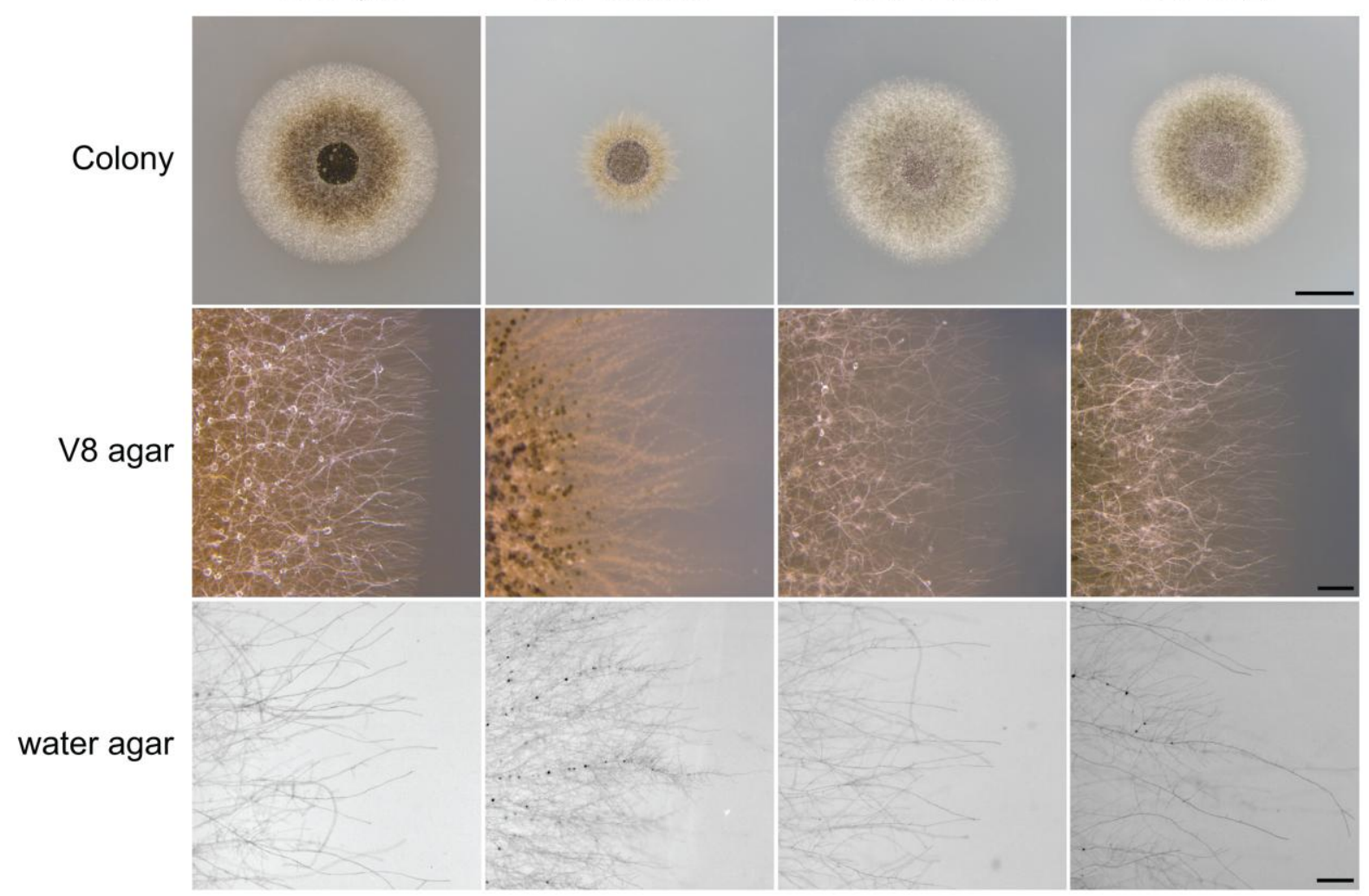




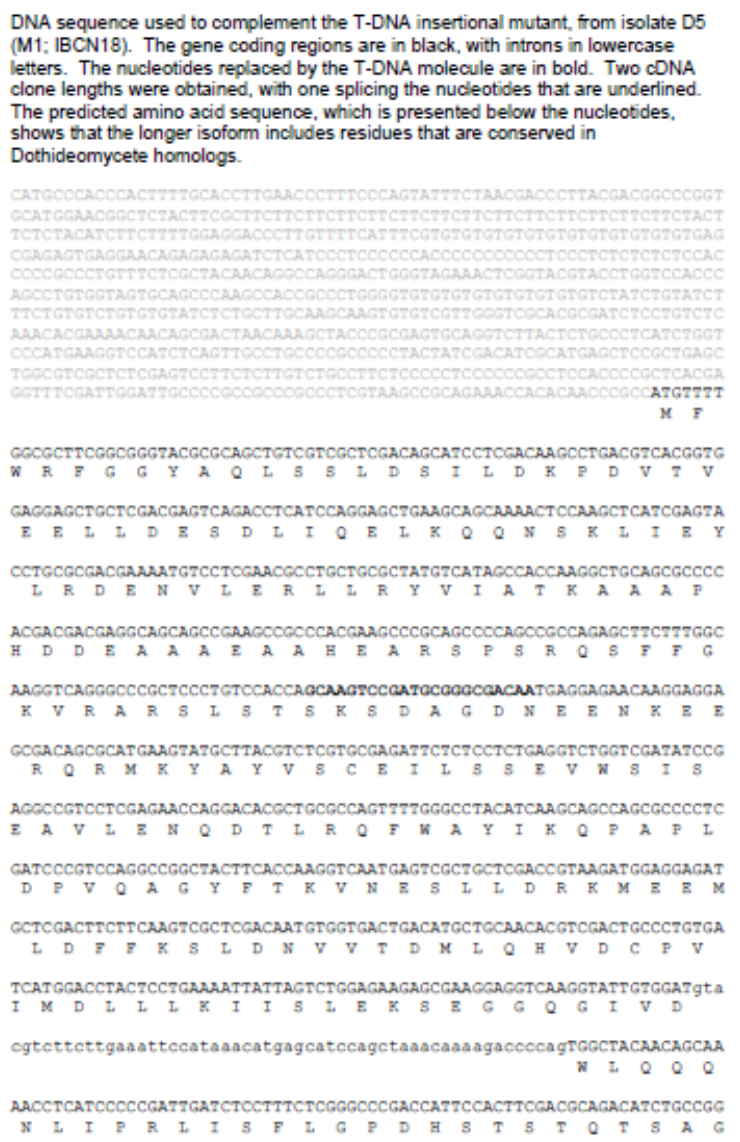

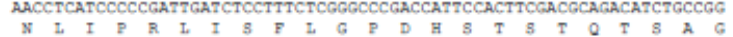

CGATITCCTCAAGGCCATCATCACCATATCTGCGAA GCCCACCACACAAGACCAGTCTGZGATCGGCC

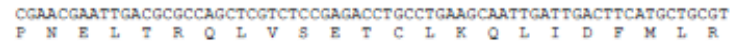
OGTGGGAACCCGZ7GACZGZAOCOCTTGGTATCATTATCCAAGZCATCOCCAMAMACAAZTCAGACZA

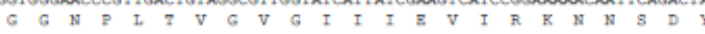
CGACCTGGAGARZCAAAZCGGACOCGTCCCANAGARTZCZGAZCOCATTTACCTAGGCACAZ7ACZAC

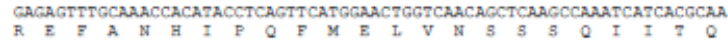
ACOGATGGCAGCACGACGACGAAGAAACGCGAGCTCAAGACGGCCTTTOOCCGAAAGATZ GAGCCGCT TOGATTTGACCGAT7CAAGACTTGTCAACTCATGGCCGAAZGCTACACTOCAGCAACAZGGCCCTAC D R F K T C E L TCAACGAACGTGGGAGZGAGOCCGAOCT GAGGAGGCGGGAZGCCGACOOCGAACGTCTCAAGGCACAC

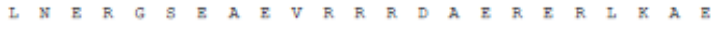

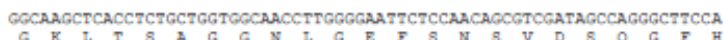
CCATGCACGRGCACCAICCATCGACTOGCCTGCGGA GATCAAGCCATTOCACGTACAGAATAGTGCGG
H A R A P ATGACGACTTRGAAAGGZZCATTOCTCCCCGAAGTCGCCATCCAGTCGCCCAACGATACGZCGCCCGGAC AACGAGCAMATCGGCGAGCCACTACAACGTTCACCCMAAGZCAZ CCCCAACGMATCCCCZGCCCGGAA $K$ E Q I G $E$ P $T$ F

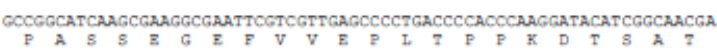
CAGAGTCGACCAGCAGCACZ COCAACOCGGCAGATGATGCCGAGTCACCTACGTCGGCTGGACZGZCT

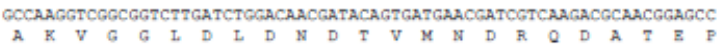
TACANAAATAGAGGCTGCAACCAAAGACCTICCTICTCZCTZGACGCAACAACTTAGCCAATCZZCCA AGACCGACGATCZ7CCZGAACCACTATCACCACATGAGGAZGAZAACOCTGCGCCACTCZ7CGCGAAT

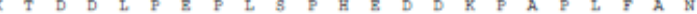

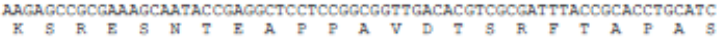




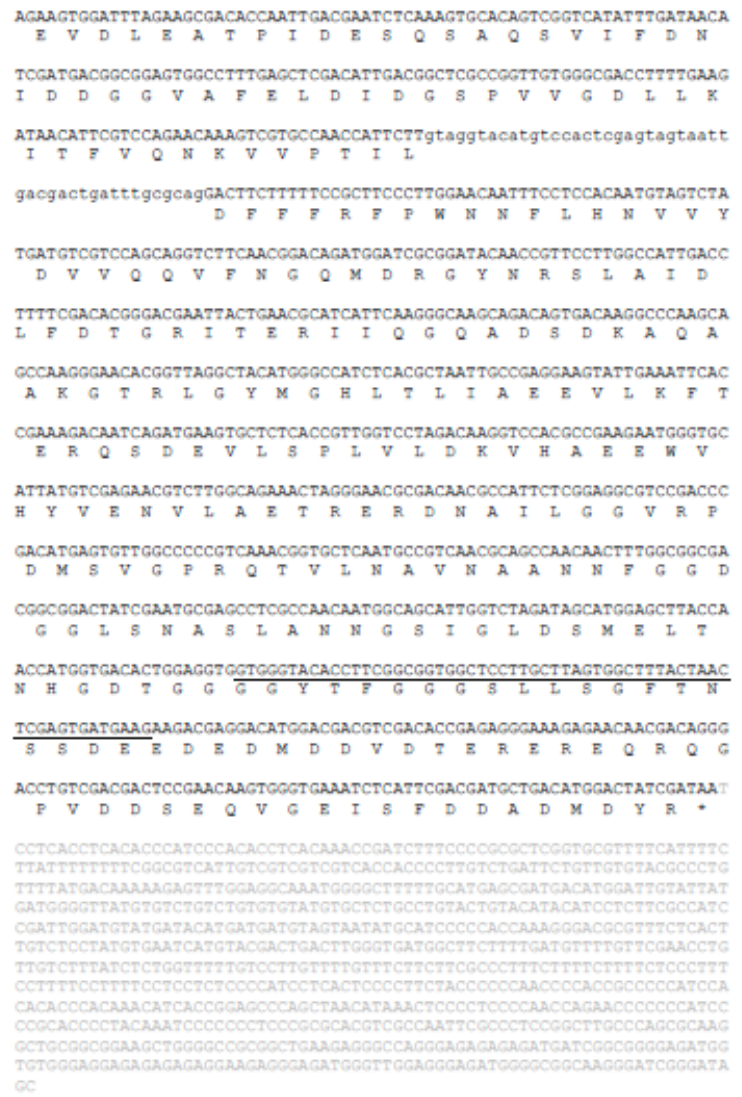




\section{University Library}

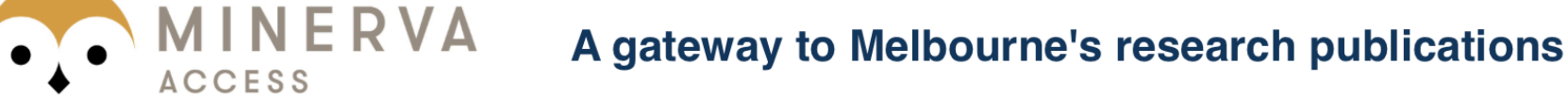

Minerva Access is the Institutional Repository of The University of Melbourne

Author/s:

Urquhart, AS;Idnurm, A

Title:

Sit4-Associated Protein is Required for Pathogenicity of Leptosphaeria maculans on Brassica napus

Date:

2017-12-01

Citation:

Urquhart, A. S. \& Idnurm, A. (2017). Sit4-Associated Protein is Required for Pathogenicity of Leptosphaeria maculans on Brassica napus. CURRENT MICROBIOLOGY, 74 (12), pp. 1438-1446. https://doi.org/10.1007/s00284-017-1338-3.

Persistent Link:

http://hdl.handle.net/11343/282707 